\title{
A CHROMOSOMAL KARYOTYPING STUDY IN MALE WITH PRIMARY INFERTILITY IN A WESTERN WEST BENGAL POPULATION
}

\author{
Abhijit Ray', Dhruba Mandal'2, Arpan Kumar Goswami', Panchanan Kundu ${ }^{4}$
}

1 Associate Professor, Department of Anatomy, Calcutta National Medical College, Kolkata, West Bengal, India. ${ }^{2}$ Associate Professor, Department of Anatomy, Bankura Sammilani Medical College, Bankura, West Bengal, India. ${ }^{3}$ Assistant Professor, Department of Anatomy, Bankura Sammilani Medical College, Bankura, West Bengal, India. ${ }^{4}$ Professor, Medical Superintendent Cum Vice Principal, Department of Anatomy, Bankura Sammilani Medical College \& Hospital, Bankura, West Bengal, India.

\section{ABSTRACT}

\section{CONTEXT}

It is interesting that the primary infertility is a major problem in a society like ours where the population is going to be exploded. It is because that infertility severely affects the family or couples psychological harmony, sexual life \& social status. Of the many factors responsible for primary male infertility which may be manifested as azoospermia or oligozoospermia, one of the important etiological factors is genetic abnormality affecting the $Y$ chromosome. Among the different parameters known to be responsible for normal spermatogenesis, a small region in the long arm of Y chromosome, containing genes or gene cluster, defined as 'Azoospermia Factor' (AZF) is definitely maintains the normal spermatogenesis to occur. Any abnormality in that part of the Y chromosome in the form of deletion or deviation of normal gene arrangement produces azoospermia or oligozoospermia and subsequently produces primary male infertility.

\section{SETTINGS}

Bankura Sammilani Medical College and Hospitals, Bankura, West Bengal.

\section{DESIGN}

Simple random sampling method.

\section{DURATION OF STUDY}

November 2013 to march 2015 (One and a half year).

\section{METHOD}

80 males suffering from primary infertility with azoospermia or oligozoospermia were selected attending the antenatal outpatient department.

\section{STATISTICAL ANALYSIS}

$2.5 \%$ patients showed numerical chromosomal abnormality i.e. Klinefelter syndrome (47XXY). Structural abnormalities were detected in $3.75 \%$ patients in the form of deletion in the long arm of Y chromosome and ring chromosome.

\section{RESULT}

Out of 80 patients 5 patients showed chromosomal abnormalities in the form of both numerical as Klinefelter syndrome $(2$ patients) \& qualitative as deletions (2 patients) \& ring chromosome (1 patient).

\section{CONCLUSION}

Y chromosomal abnormalities either numerical or structural, is an important factor of male infertility as oligospermia or azoospermia. These abnormalities can be easily detected by simple aids like karyotyping and does not require high-fi costly instruments.

\section{KEYWORDS}

Male infertility, Oligozoospermia, Azoospermia, Y Chromosome Deletion, Karyotype.

HOW TO CITE THIS ARTICLE: Ray A, Mandal D, Goswami AK, et al. A chromosomal karyotyping study in male with primary infertility in a Western West Bengal population. J. Evolution Med. Dent. Sci. 2016;5(21):1071-1074, D0I: 10.14260/jemds/2016/248

Financial or Other, Competing Interest: None.

Submission 29-01-2016, Peer Review 23-02-2016,

Acceptance 01-03-2016, Published 11-03-2016.

Corresponding Author:

Dr. Dhruba Mandal,

Rabindrapalli,

Burdwan-713101,

West Bengal,

India.

E-mail: mandaldhruba@yahoo.com

DOI: $10.14260 /$ jemds/2016/248

\section{INTRODUCTION}

Infertility, a major reproductive health problem and a grave social stigma, is defined as "The inability to conceive even after 12 months of regular unprotected sexual intercourse,". ${ }^{1}$ which affects the psychological harmony, sexual life and social status in the affected couple. Primary infertility refers to couples who have never achieved a pregnancy. Secondary infertility implies that at least one previous conception has taken place, but failure to conceive subsequently; the previous conception may or may not lead to viable birth of the baby. 
The primary infertility varies between $8-12 \%{ }^{2,3}$ in the married couples of reproductive age. A male factor is solely responsible for in about $30-40 \%$ of primary infertility

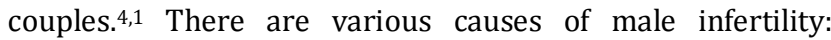
anatomical, environmental, occupational, genetic and so on. Recent development in the field of cytogenetic \& chromosomal study, a good number of male infertility partners have genetic or chromosomal disorders. The overall incidence of genetic factors in infertile males ranges from 2 to $8 \%$ with a mean value of $6 \% .^{5}$ Previously, infertility was considered to be a female problem, and social stigma as well as physical and mental torture were born to the females only. This is no more true and it has led to the fact that $40-50 \%$ of infertility is due to male factor. ${ }^{6}$

\section{Review of Literatures}

Recent advances in the field of genetics throw light on the aetiology of many unknown causes of the primary male infertility. Tiepolo \& Zuffardi.7 in 1976 were the first to indicate a positive correlation between deletion in the long arm of Y chromosome \& primary male infertility. They observed a large deletion in the heterochromatin region (Yq12) in 6 sterile males with azoospermia by observing the karyotype of 1170 men.

They postulated that a genetic factor located in the long arm of $\mathrm{Y}$ chromosome was important for male spermatogenesis. Their findings were supported by Reijo et al published in Lancet in 1996.8 In Indian scenario, Dr. Thangaraj, Dr. Chakrabarty et al in a combined study in Hyderabad \& Kolkata analysed 340 azoospermic males found that $8.5 \%$ have Y Chromosome deletions. ${ }^{9}$

\section{MATERIALS AND METHOD}

Cases were selected amongst the male partners of the female patients attending at the out-patient Department of Obstetrics \& Gynaecology of the Bankura Sammilani Medical College, Bankura, West Bengal.

\section{Criteria of Selection}

1. Male partners of the infertile couples (Primary Infertility) who were azoospermic or oligospermic, the female partners were normal.

Azoospermia: Absence of sperm per ejaculate.

Oligozoospermia: Sperm count is less than 20 million/ml per ejaculate.

2. There were no anatomical abnormality like undescended or ectopic testis, varicocele etc. to the selected patients.

3. No past history of Mumps orchitis, undescended testis, trauma to the testis, torsion of the testis.

4. Age of Inclusion: 25-45 years.

5. Number of cases selected: 80 .

\section{The following steps were followed to carry out the} procedure:

1. Selection of patients.

2. Clinical examination of the patient.

3. Collection of semen in proper way \& semen analysis.

4. Collection of venous blood for karyotyping and GiemsaTrypsin banding (G-T banding): $5 c c$. of venous blood was collected in a sterile heparinised syringe by venepuncture from antecubital vein. 10-12 drops of collected blood were added to a sterile container containing 5cc. T.C. 1999 \& $9.2 \mathrm{ml}$. of Phytohaemagglutinin, then $1 \mathrm{cc}$. of auto-serum was added.
The culture container was then incubated at $37^{\circ} \mathrm{C}$ for 72 hours. Then $0.04 \mathrm{ml}$ Colchicine solution was added to the cultured \& incubated solution. Two hours after, the cellsuspension was transferred to a centrifugal machine \& centrifuged at 800 r.p.m. The supernatant was discarded and to the cell pellets $5 \mathrm{ml}$ of hypotonic $\mathrm{KCl}$ solution was added \& incubated the solution. Then the resultant solution was harvested by repeated use of fixatives (Methanol: Glacial Acetic Acid=3:1) \& repeated centrifugation alternatively. 8-10 drops of cell pellets were allowed to drop by a Pasteur pipette from $2 \mathrm{ft}$. above on to a well cleaned \& fixative-smeared dry slide held horizontally by a forceps. After drying, the slide was stained by Giemsa stain ( $5 \mathrm{cc}$. of Giemsa stain $+45 \mathrm{cc}$. of phosphate buffer), seen under compound microscope to view the primary patterns of chromosome (Karyotyping). Then another harvested slide prepared in above mentioned way of the same cultured solution was subject to G-T banding by using prior treatment with Trypsin solution $(0.005 \%)$ \& subsequent Giemsa staining to know any structural abnormalities.

5. Collection of blood for hormonal assay, e.g. Thyroid profile, FSH, LH \& Testosterone.

\section{OBSERVATION AND RESULT}

A total number of 80 male candidates suffering from primary infertility $(\mathrm{N}=80)$ were selected. Out of 80 patients two patients showed numerical abnormality (47XXY karyotype). Three patients showed structural abnormality: two of them showed minor deletion in the short arm of Y chromosome; one of them showed 46XY with ring chromosome of the Y. Other patients were karyotypically normal (46XY).

\begin{tabular}{|c|c|c|}
\hline Karyotype & $\begin{array}{c}\text { Total No. of } \\
\text { patients (n=80) }\end{array}$ & Percentage \\
\hline Normal & 75 & $93.75 \%$ \\
\hline Abnormal & 05 & $06.25 \%$ \\
\hline \multicolumn{2}{|c|}{ Table 1: Distribution of the chromosomal study } \\
\hline
\end{tabular}

\begin{tabular}{|c|c|c|c|}
\hline $\begin{array}{c}\text { Type of } \\
\text { abnormalities }\end{array}$ & & $\begin{array}{c}\text { No. of } \\
\text { patients } \\
\text { with } \\
\text { abnormal } \\
\text { karyotype } \\
\end{array}$ & Percentage \\
\hline Numerical & $\begin{array}{l}\text { Klinefelter } \\
\text { syndrome }\end{array}$ & 2 & $2.5 \%$ \\
\hline \multirow{2}{*}{ Structural } & $\begin{array}{c}\text { Ring } \\
\text { chromosome }\end{array}$ & 1 & $1.25 \%$ \\
\hline & Deletion & 2 & $2.5 \%$ \\
\hline
\end{tabular}

In the present study $2.5 \%$ patients suffering from primary infertility showed numerical genetic abnormality i.e. Klinefelter syndrome (47XXY). The candidates exhibited azoospermia. All of them had very high gonadotrophins and significantly low testosterone level. Structural abnormalities were detected in $3.75 \%$ patients in the form of deletion in the long arm of Y chromosome and ring chromosome. All of them showed azoospermia but normal gonadotrophins and testosterone level. The rest of the selected patients i.e. $93.75 \%$ had oligozoospermia or azoospermia but no genetic defect had been found. 


\section{DISCUSSION}

The normal human contains 46 chromosomes in the cell nucleus out of which forty four are autosomes and rest two are sex chromosomes $\mathrm{X}$ and $\mathrm{Y}$. The male sex chromosomal pattern is $\mathrm{XY}$ and females have $\mathrm{XX}$. As only males have $\mathrm{Y}$ chromosome, the genes in this chromosome are supposed to be involved in male sex determination \& development. The regions that are responsible for loci of genes that determine the male sex character \& spermatogenesis are traced to be present in a small area in the long arm of $\mathrm{Y}$ chromosome and are called Azoospermia Factor A, B \& C [AZF a, b \& c].

Deletions in the AZF regions may affect several numbers of genes resulting in impaired production of proteins which help in spermatogenesis. This results in both gross reduction of spermatogenesis leading to oligozoospermia or azoospermia and/or functional defects in sperm if present leading to primary male infertility that we can call Ychromosome infertility. Deletion are usually in the form of microdeletion that can only be evaluated by PCR technique, using sequence tagged sites (STS) as markers. Interestingly in our study, by simply using the G-T banding we found 2 patients have macrodeletion in the long arm of $\mathrm{Y}$ chromosome that is demonstrable in karyotyping.

Klinefelter syndrome (KS), 47XXY, is the most frequent sex chromosome aberration in males, affecting 1 in 660 newborn boys. The syndrome is characterized by testicular destruction with extensive fibrosis and hyalinization of the seminiferous tubules resulting in small testes, hypergonadotropic hypogonadism, and azoospermia leading to primary male infertility. ${ }^{10,11}$

Ring chromosome may affect the AZF regions of $\mathrm{Y}$ chromosome resulting in testicular failure with azoospermia or oligozoospermia. ${ }^{12}$

Lumenfeed B et al.13 investigated the causes and problems of the infertility in 1993. In different studies around the world the male factor was responsible in $23 \%$ to $46 \% .{ }^{5}$ Out of this, genetic abnormalities were reported in different studies ranges from $10-15 \% .{ }^{14}$ In the present study, it is found to be lower than the other studies. Yoshida. ${ }^{15}$ studied 1007 patients. He reported inversion in 05 patients $(0.49 \%)$. Carp et al. ${ }^{16}$ studied 103 infertile males; they found inversion in 2 (1.94\%) patients.

Drugkar Amoz, Gangane S D. 5 in their study found inversion in $1.42 \%$ patients. In the present study, the inversion is found in one patient out of 80 selected patients (1.25\%). So our study is correlated with the study of Carp et al and Gangare S D. The study of Mitra et al. ${ }^{17}$ deletion of the Y chromosome is found to be $5.29 \%$. In our study, the Y chromosome deletion is found in $2.5 \%$ cases.

\section{CONCLUSION}

Karyotyping and Y chromosome study should be an important second line investigation to determine the causes of male infertility in patients with azoospermia or oligozoospermia. The lower percentage reported in our study possibly due to lack of use of PCR and FISH technique in the study of chromosomal analysis. Detection of genetic factors avoids unnecessary normal and other unproven treatment in a vain attempt to boost the sperm count. This also helps to predict the effectiveness of assisted reproduction in men with genetic abnormality. Another important matter of thought is the role of heredity in $\mathrm{Y}$ chromosome infertility.
If $\mathrm{Y}$ chromosome infertile male father gives a child by assisted reproduction, the genetic abnormalities may pass to a son but not to a female child. This should be borne in mind during assisted reproduction. In the economically poor areas in India where sophisticated instruments are not available specially in rural area, simply a centrifuge machine, a compound microscope and some reagents can make a preliminary genetic diagnosis in primary male infertility cases which help in prevention of unnecessary and costly investigations.

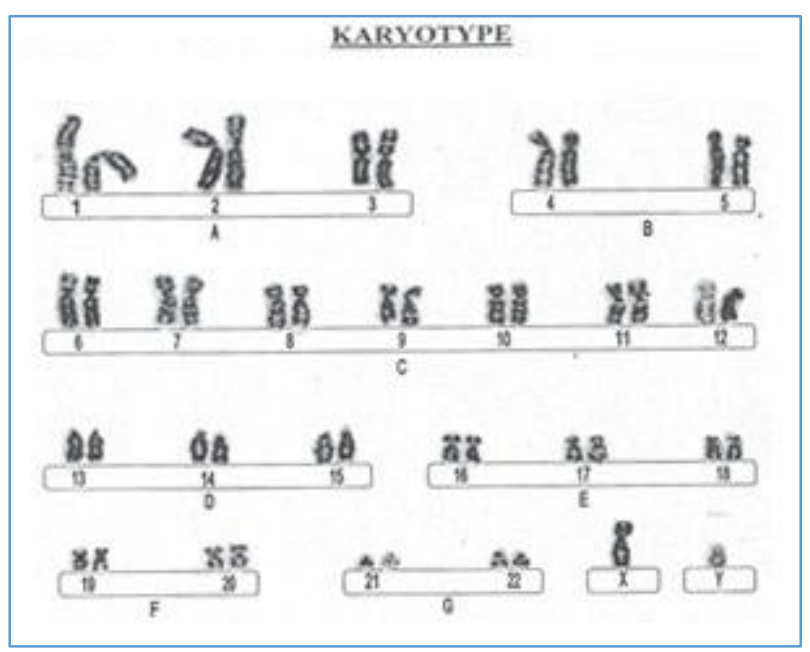

Fig. 1: Showing Normal Karyotype

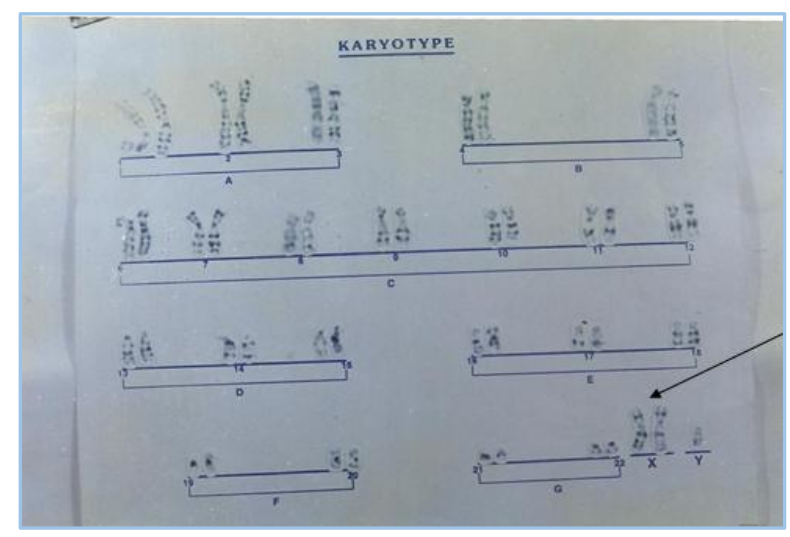

Fig. 2: Showing Klinefelter Syndrome (47XXY)

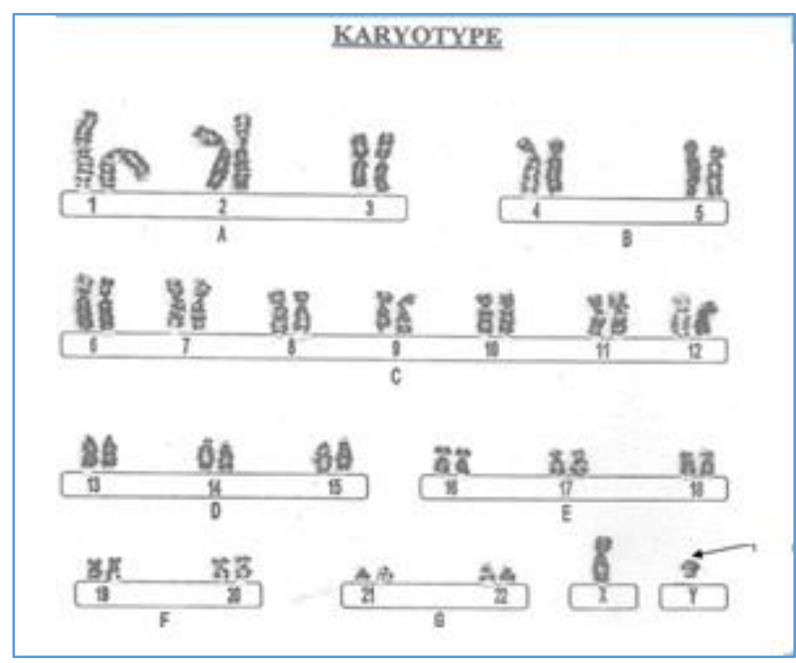

Fig. 3: Showing Deletion in long arm of $Y$ chromosome (Indicated by Arrow) 


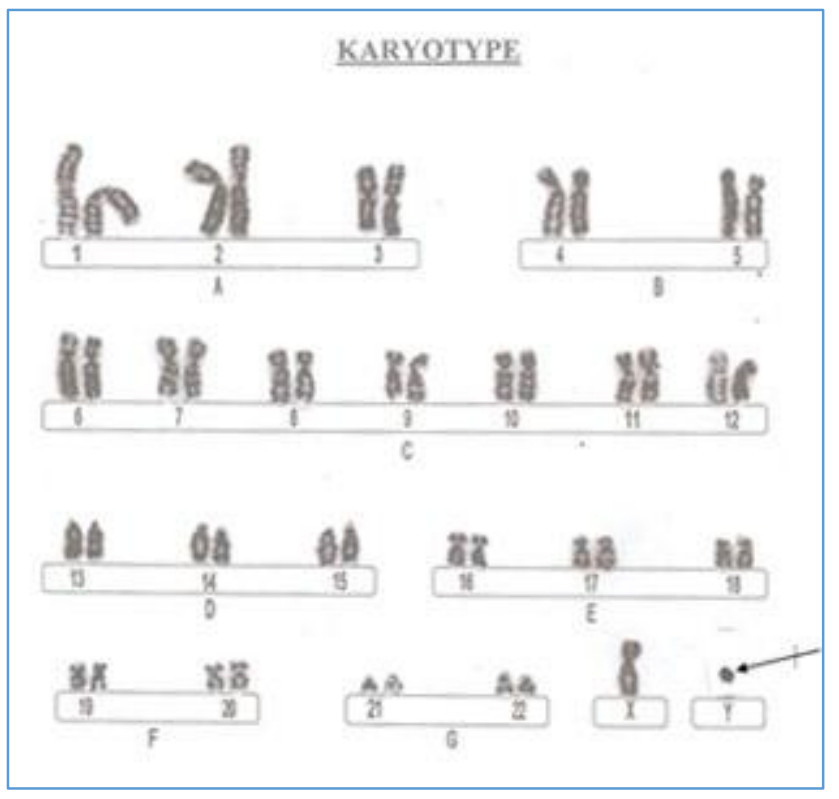

Fig. 4: Showing ring Y chromosome (Indicated by arrow)

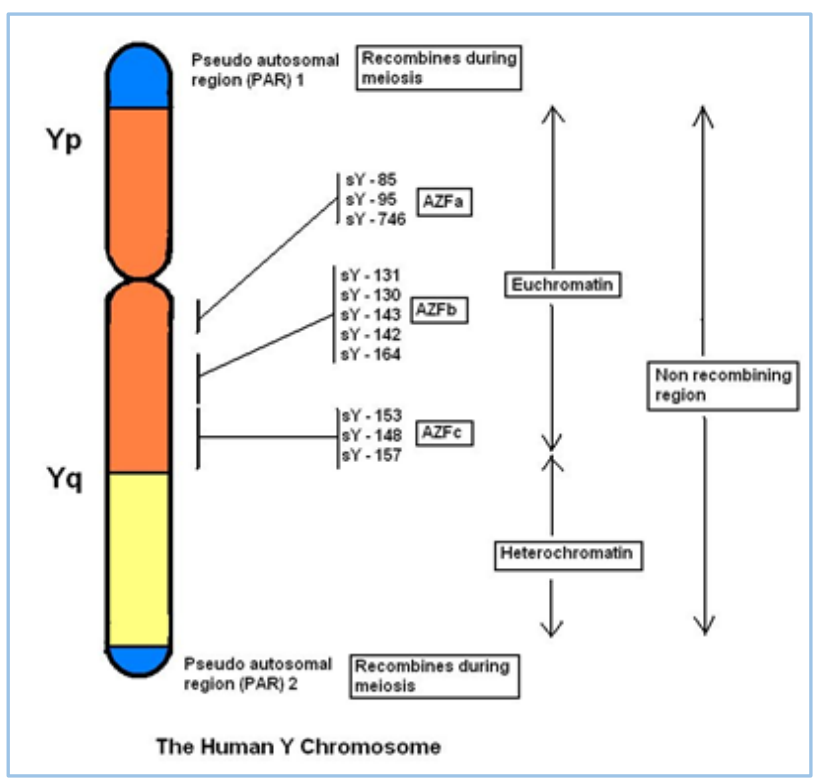

Fig. 5: Human Y chromosome (Diagrammatic)

\section{REFERENCES}

1. Hiralal K, Datta's DC. Text book of Gynaecology. Delhi: Jaypee brothers medical publishers private limited, 2014; $6^{\text {th }}$ edn:pp 217.
2. Sciara J. Infertility: an international health problem. int J Gynaecol Obstet 1994;46:155-63. (Pub Med).

3. New Delhi. Population council \& infertility. Looking back \& looking forward: a profile of sexual and reproductive health in India. 2004;11:67-72.

4. American Urological Association. The optimal evaluation of the infertile male: AUA best practice statement. 2010;03-05.

5. Drugkar Amol Z, Gangane SD, More Rahi M, et al. Cytogenetic study in male infertility. IOSR-JDMS 2013;5(2):05-11.

6. Speroff L, Glass R, Kase N. Clinical gynaecology endocrinology and infertility. 1989; $4^{\text {th }}$ ed:564-582.

7. Tiepolo L, Zuffardi O. Localization of factors controlling spermatogenesis in the non-fluoroscent portion of human Y-chromosome long arm. Hum Genet 1976;34:119-24.

8. Reizo R, Alagappan RK, Patrigio P, et al. Severe oligozoospermia resulting from deletions of azoospermia factor in Y chromosome. Lancet 1996;347:1290-1293.

9. Thangaraj K, Gupta NJ, Pavani K, et al. Y chromosome deletions in azoospermic males in India. $\mathrm{J}$ androl 2003;24(4):588-597.

10. Aksglaede L, Juul A. Therapy of endocrine disease: testicular function \& fertility in men with klinefelter syndrome. Eur J Endocrino 2013;168:67-76.

11. Bojesen A, Juul S, Gravoho CH. Prenatal \& postnatal prevalence of klinefelter syndrome. $\mathrm{J}$ of Clinical endocrinology \& metabolism 2003;88:622-626.

12. Xueyan C, Gordana R, Jennifer L, et al. Chromosomal abnormalities in 2 case reports of testicular failure. J Androl 2011;32:226-231.

13. Lunenfeld B, Insler V. Infertility in male and female: the dimension of the problem. Churchill Livingstone, Edinburgh, 1993;2nd ed:Pp 3-10.

14. Fadtalla Elfatep, Wang T, Zhang Z, et al. Influence of genetic abnormalities on semen quantity and male infertility: a four years prospective study. Iran J Reprod Med 2014;12(2):95-102.

15. Yoshida A, Miura K, Shirai M. Cytogenetic survey of 1007 infertile males. Urologia internationalis 1997;58(3):16676.

16. Carp H, Feldman B, Olesner G, et al. Parental karyotype and subsequent live births in recurrent miscarriage. Fertility sterility 2004;81(5):1296-1301.

17. Mitra A, Dada R, Rajeev K, et al. Screening for $Y$ chromosome microdeletion in infertile males: utility of simplified multiplex PCR. Indian J Med 2008;127:124-132. 